\title{
La Reinvención del Dinosaurio: Entre la Nostalgia y el Pragmatismo del Partido Colorado en Paraguay
}

\author{
The Reinvention of the Dinosaur: Between Nostalgia and \\ Pragmatism of the Colorado Party in Paraguay
}

\section{Sarah Patricia Cerna Villagra Juan Mario Solís Delgadillo}

\section{Resumen}

El presente trabajo busca explicar con base en evidencia empírica comparada las características, el contexto, las reglas y los resultados del proceso electoral paraguayo del año 2013. Para ello, se recurre a la revisión de los datos electorales de esta última elección, así como de los procesos previos de los años 1993, 1998, 2003 y 2008. Los principales hallazgos indican que tras el último proceso electoral en Paraguay se pueden hacer cuatro consideraciones: a) que el único partido con una estructura y efectiva presencia nacional es la ANR; b) que el PLRA es un partido incapaz de crecer, pero que mantiene su voto cautivo; c) que UNACE y PPQ son partidos en vías de extinción en cuanto se han vaciado de contenido a raíz de la ausencia de sus líderes históricos; y d) que la izquierda paraguaya, a pesar de sus diferencias, ha tenido un crecimiento interesante en las zonas rurales, pero también entre grupos de las clases medias urbanas menos conservadoras y religiosas.

\section{Palabras clave}

Elecciones; Financiación; Candidatos; Distribución del Poder.

\begin{abstract}
The present paper seeks to explain, based on compared empirical evidence the characteristics, the context, the rules and the results of the Paraguayan electoral process of 2013. To process this information, the review of the electoral data was utilized, up to the last election, as well as the previous processes of 1993, 1998, 2003 and 2008. The main findings indicate that after the last election in Paraguay, four types of considerations can be made: a) the only party with a national structure and effective presence is the ANR; b) the PLRA is a party unable to grow, but maintains its captive vote; c) the UNACE and PPQ parties are in danger of extinction as they have been emptied of content due to the absence of its historical leaders; and d) that the Paraguayan left, despite their differences, has had an interesting growth in rural areas, but also between groups of urban middle classes less conservative and religious.
\end{abstract}

\section{Keywords}

Elections; Financing; Candidates; Power Distribution. 


\section{Introducción}

Las elecciones generales de Paraguay de 2013 estuvieron signadas por una serie de factores que deben ser tenidos en cuenta a la hora de explicar el regreso al poder de la Asociación Nacional Republicana (ANR). Ellos son el polémico proceso de juicio político que culminó con la destitución del entonces presidente constitucional Fernando Lugo, los escándalos de corrupción del efímero gobierno liberal de Federico Franco, las múltiples divisiones al interior de los partidos adversarios al coloradismo, los constantes ataques personales entre los principales líderes políticos, la muerte del candidato presidencial de la Unión Nacional de Ciudadanos Éticos (UNACE) en un accidente aéreo, el sentimiento de nostalgia de una buena parte del electorado paraguayo sobre la "estabilidad" del coloradismo y la irrupción de una figura exógena al sistema de partidos, caracterizada por su éxito empresarial, su carisma y su empatía que fue cooptada por el Partido Colorado, ante la ausencia de liderazgos fuertes para que los representara y encabezara el retorno al Palacio de López tras cinco años en la llanura.

El presente artículo busca explicar, con base en evidencia empírica comparada, las características, el contexto, las reglas y los resultados del proceso electoral paraguayo de 2013. Para ello se recurre a la revisión de los datos electorales de esta última elección, así como de los procesos previos de los años 1993, 1998, 2003 y 2008. De igual manera se hace una inmersión en la literatura que en años recientes se ha escrito sobre la realidad política del país. La hipótesis que guía este trabajo es que ante el escenario revuelto que culminó con el impeachment y posterior destitución del presidente Fernando Lugo se abrió una ventana de oportunidad que favoreció el retorno al poder del Partido Colorado, aun y cuando esta agrupación atravesaba por una crisis de liderazgos que resolvió de manera pragmática al entregar la candidatura presidencial a un outsider que ofrecía la "estabilidad" de la otrora "pax colorada" y la "ilusión" que se había perdido tras los modestos resultados del gobierno de la APC.

El trabajo se divide en nueve partes en las que se aborda: las características del sistema de partidos paraguayo; el contexto político del periodo previo a las elecciones; el juicio político a Fernando Lugo; los programas o propuestas ofertadas; el proceso de selección de candidatos; las reglas del juego y la financiación de las campañas; los resultados electorales; las implicaciones que tiene el regreso de la ANR al poder y, finalmente, unas conclusiones con base en los resultados desde una perspectiva diacrónica. 


\section{Cultura politica y bipartidismo: caracteristicas del sistema de partidos paraguayo}

Paraguay es un país cuyos problemas tienen tres caras: a) una perniciosa estructura socioeconómica; b) un acentuado clientelismo; y c) un problema sistémico de agencia (BARREDA y BOU, 2010). Desde ese punto de vista, Abente Brun (2012) subraya que esto es así porque los partidos políticos tradicionales no han tenido incentivos para mejorar la calidad de la democracia, y que por el contrario, son los más firmes impulsores del mantenimiento del statu quo y los principales opositores a cualquier proyecto de reforma que altere este modelo de relación social.

$\mathrm{Si}$ a estas observaciones se agrega que una de las características más sobresalientes de la cultura política paraguaya gira en torno a la importancia que se le da a los liderazgos fuertes y carismáticos (UHARTE POZAS, 2012) tenemos como resultado una sociedad en la que priman las relaciones de supra a subordinación. La propia historia del país ofrece bastantes ejemplos al respecto, aunque seguramente sea la figura del general Alfredo Stroessner la más llamativa de todos ellos, dado el enorme dominio que ejerció, la estructura política de la que se valió, la impronta ideológica que imprimió y las herencias autoritarias - institucionalizadas y sociabilizadas - que dejó.

Paraguay posee uno de los sistemas de partidos más longevos de la región, pero no por ello uno de los más estables. En efecto, tanto la ANR (Partido Colorado) cuanto el PLRA (Partido Liberal) han representado históricamente a las clases dominantes en conflicto desde mediados del siglo XIX. En un país en el que el poder está vinculado a la propiedad agrícola, las élites de estos partidos han sido, quien másquien menos, las principales protagonistas del progresivo acaparamiento de tierras, que con el paso de los años se ha convertido en el corazón de los problemas estructurales del Paraguay.

En ese sentido, es interesante observar que entre Colorados y Liberales no existe una significativa distancia en términos ideológicos, en tanto ambos partidos están claramente ubicados a la derecha del espectro político. Para el año 2008, los legisladores paraguayos ubicaron en promedio a la ANR en 6,33, y al PLRA en 6,78 en un continuo de uno a diez en dónde uno sería extrema izquierda y diez extrema derecha. No obstante, es interesante observar cómo es que desde 1993 hasta el 2008, se han cruzado las posiciones, de tal suerte que la ANR ha experimentado un ligero viaje al centro, mientras que el PLRA ha transitado más a la derecha, según se observa en las series temporales del Proyecto Élites Parlamentarias Latinoamericanas de la Universidad de Salamanca (PELA) (VILLAGRA CERNA y SÓLIS DELGADILLO, 2012; PELA, 2008). 
Gráfico 1 - Desplazamiento ideológico de los partidos tradicionales paraguayos

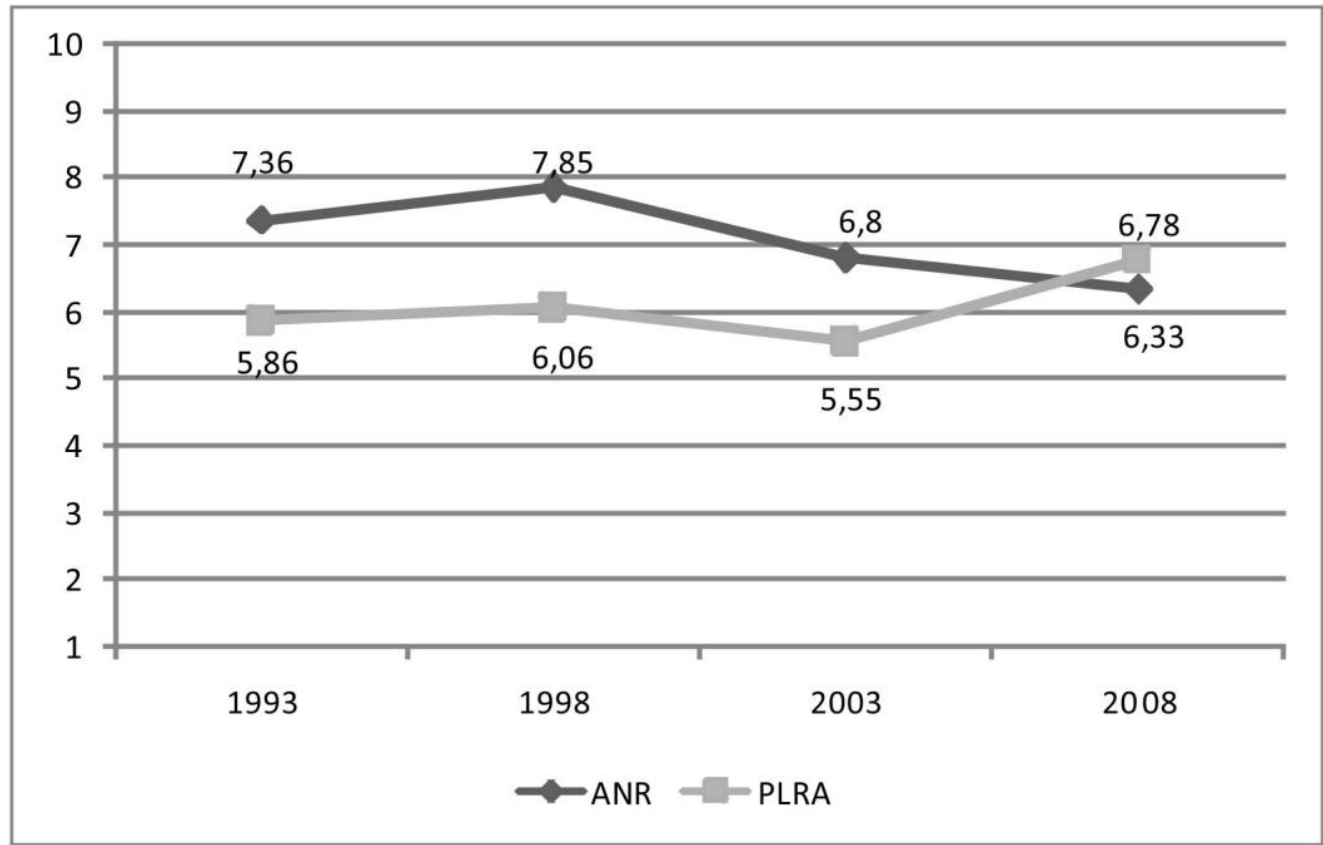

Fuente: Elaboración propia con base en los datos de PELA (2008).

Por otro lado, si bien indicadores como el Número Efectivo de Partidos (NEP) expresa que en Paraguay existen más partidos con presencia significativa en la arena política, cabe destacar dos cosas: a) que esos partidos (UNACE y PPQ, principalmente) no alcanzan a competir seriamente frente a los partidos tradicionales; y b) que ambas agrupaciones comparten con la ANR y el PLRA el espacio ideológico de la derecha. Esto en sí es muy llamativo porque deja al descubierto que la izquierda paraguaya ${ }^{1}$ ha tenido muchas dificultades para abrirse paso en un sistema dominado por partidos/actores conservadores, pero además, que ha sido incapaz de articular liderazgos en una sociedad que le ha dado la espalda, muy probablemente por la construcción imaginaria que durante los años de Stroessner se hizo de este campo ideológico.

\section{Escenario politico previo a las elecciones generales de 2013}

Hacia el año 2008, el desgaste del Partido Colorado, tras más de 60 años en el poder, comenzó a hacerse evidente en la medida en que vio mermada su facultad de

\footnotetext{
${ }^{1}$ La izquierda no ha podido recuperarse de la desarticulación que sufrió durante el stronismo con la persecución de sus líderes, la proscripción de los principales partidos de izquierda y su tendencia histórica a la fragmentación, razones que explican su debilidad como fuerza política.
} 
ser la agencia de colocación de empleo estatal por excelencia, perdiendo con ello la capacidad de mantener fieles a sus votantes. Junto con ello el país sostenía años de crecimiento económico exiguo, presentaba problemas serios de desempleo y acarreaba conflictos sociales y políticos que los propios legisladores reconocían. En ese contexto, surgió la figura de Fernando Lugo, un ex obispo de una de las diócesis más pobres del país, quien demostraba "suma habilidad" para articular a sectores políticos ideológicamente en las antípodas desde los partidos más a la izquierda del espectro hasta la derecha tradicional del PLRA (UHARTE POZAS, 2012).

La alternancia política de 2008, además de poner fin a la hegemonía colorada, supuso también el éxito de una coalición contra natura, y muy en especial, el triunfo de un outsider. Este proceso, además de novedoso, fue inusitado dadas las distintas corrientes de pensamiento y la procedencia de sus actores principales, en especial Fernando Lugo y Federico Franco; presidente y vicepresidente, respectivamente.

$\mathrm{Si}$ a esto se suma que la APC sólo fue concebida como un vehículo para ganar la elección presidencial del 2008, y que cada partido de la coalición tendría su propia agenda en el Poder Legislativo, no resulta extraño que las relaciones entre estos partidos inexorablemente estaban destinadas al desgaste y la erosión de los apoyos hacia el Ejecutivo. Sin embargo, esto no justifica la desbandada de los liberales para activar la figura del juicio político contra el presidente.

De acuerdo con los datos ofrecidos por el PELA (2008), si se observa el porcentaje de diputados que se consideraban oposición cuando recién comenzó la legislatura en 2008, se tiene que el 58\% de éstos así se posicionaban. Esto representaba la práctica totalidad de los diputados de la ANR, la UNACE y el Partido Patria Querida (PPQ). Si este guarismo se compara con los votos a favor del juicio político entre los diputados se tiene que tras cuatro años en el gobierno, Lugo quedó prácticamente abandonado, pues sólo cuatro diputados respaldaron al presidente 2 .

Por otro lado, si se echa un vistazo a la administración pública en general, las condiciones en las que le tocó gobernar a Lugo eran bastante complejas teniendo en cuenta que las instituciones públicas estaban - y lo siguen estando - colonizadas por los partidos tradicionales. En un entorno en el que priman las redes clientelares, las cadenas de favor y una aceitada estructura de corrupción ${ }^{3}$, salta a la vista la poca confianza que los propios legisladores profesan a la mayoría de las instituciones del país, salvo a la Iglesia Católica que tradicionalmente ha representado los valores más

\footnotetext{
${ }^{2}$ La pregunta que se le realiza a los diputados es muy concreta: “¿Y Usted se considera del gobierno o la oposición?"

${ }^{3}$ Basta con echar un vistazo al índice de corrupción de Transparencia Internacional (2013), que sitúa a Paraguay como uno de los países más corruptos del mundo (ranking 150 de 177).
} 
conservadores y el Congreso cuya valoración por parte de los legisladores es muy positiva como producto del "efecto entrevista"4.

En ese sentido, con relación a la confianza en las instituciones llama poderosamente la atención cómo es que a raíz de 2008 la confianza hacia las Fuerzas Armadas entre los diputados dio un salto cualitativo, pasando de $38,4 \%$ de legisladores que confiaban mucho o bastante en ellas en 1998 y un $29,2 \%$ que lo hacía en 2003 a un $72,3 \%$ en 2008 ; y al mismo tiempo cómo descendió la confianza hacia el Presidente de la República de un 54,7\% y 82,3\% en 1998 y 2003, a un 48,6\% en 2008 (PELA, 2008; CERNA VILLAGRA y SÓLIS DELGADILLO, $2012)^{5}$.

Los últimos datos referidos demuestran que Lugo era una especie de "intruso en casa ajena" que no merecía la confianza de los actores tradicionales, quienes además radicalizaron algunas de sus posturas en una clara actitud defensiva en la preservación de sus intereses tanto de clase dominante cuanto de carácter patrimonial.

De esta manera, la amenaza de activar la figura del juicio político al presidente Lugo fue permanente y revela el nivel de confrontación entre el Ejecutivo y el Legislativo, en especial en lo que toca a las reformas que el presidente Lugo consideraba impostergables, como la reforma agraria ${ }^{6}$. Esto quiere decir que la resistencia de una minoría privilegiada se impuso a pesar de la urgente necesidad de redistribuir las tierras (PALAU, 2010). Sin embargo, también cabe mencionar, que el presidente Lugo no tuvo control de riesgos, lo que a la postre no sólo le costó la pérdida de los apoyos de los movimientos sociales y las organizaciones campesinas, sino incluso de sus socios de gobierno más distantes, con lo que "la tenaza implementada por liberales y colorados es pues coherente con la mínima distancia ideológica [y de intereses] que les separa” (ALCÁNTARA SÁEZ, 2012, s/p).

\footnotetext{
4 Se entiende por "efecto entrevista" a la evaluación positiva que realiza un entrevistado cuando es interrogado sobre el papel o grado de confianza que tiene en la institución en la cual se desempeña en la medida en que realiza esta valoración pensando en su propia reputación y no en elementos más objetivos. En otras palabras, implicaría que valorar mal a la institución sería como autodefenestrarse o meterse un autogol.

${ }^{5}$ La pregunta que se les formula a los legisladores es la siguiente: "Y en relación a las siguientes personas, grupos e instituciones, me gustaría saber, ¿qué grado de confianza, mucha bastante, poca o ninguna, le merece su actuación en la vida pública paraguaya?”.

${ }^{6}$ Hasta antes del juicio político del 22 junio de 2012, el Congreso había amagado 23 veces al presidente Lugo con llevarlo a esta vía por "mal desempeño” en el cargo.
} 


\section{La fagocitación del presidente: Juicio politico y consecuencias:}

El motivo que dio "origen" al juicio político fue la matanza de 17 personas entre campesinos y policías en un intento de desalojo de "campesinos sin tierra" en una controvertida propiedad ${ }^{7}$ ocupada por la agro ganadera "Campos Morombi" perteneciente a Blas Riquelme (político y empresario colorado), en la zona de YbyPyta, Curuguaty, al noreste del país. Sin embargo, éste no fue un hecho aislado, aunque sí el pretexto perfecto para echar al presidente a pocos meses de las elecciones presidenciales a celebrarse en abril de 2013.

Al ser Paraguay un país económicamente agrícola, en el que existe una fuerte concentración de tierras ( $85 \%$ de la superficie agropecuaria) en 2,6\% de las fincas (MAG, 2009), la reforma agraria planteada por Lugo era una amenaza para esta élite que en su mayoría se ha hecho de estas posesiones de manera ilegítima. Cabe señalar al respecto que en toda la transición democrática, los sucesivos gobiernos no se distinguieron de la era stronista respectoa la política agraria ya que las desigualdades permanecieron tanto en la estructura agraria como en la exclusión social de los campesinos, según los afirma Sandoval (2012).

Los esfuerzos de Lugo por sacar adelante esta reforma se vieron sistemáticamente bloqueados por una clase política que además está estrechamente ligada a las rentas del campo y del modelo sojero. De acuerdo con Uharte Pozas (2012), los avances del gobierno en materia de reforma agraria fueron muy tímidos, y hasta cierto punto contradictorios, pues éste llegó a ofrecer apoyo a los terratenientes más que recuperar tierras como ocurriera en Curuguaty ${ }^{8}$.

\footnotetext{
${ }^{7}$ Dicha propiedad posee 1748 ha. que pertenecían a la empresa latifundista la Industrial Paraguaya y fueron donadas por ésta en 1967 en compensación a otras obligaciones que tenía con al Estado. Bajo el gobierno de Nicanor Duarte en 2004, se declaran de interés social dichas tierras y se transfieren al INDERT para destinarlas a la reforma agraria, ante lo cual, el empresario colorado Blas N. Riquelme inició una demanda judicial solicitando la Usucapión de dichas tierras. El juzgado de Curuguaty con una celeridad sin precedentes otorga dichas tierras al empresario. Por su parte, el Procurador General de la República en el año 2005 interpone una acción de nulidad de juicio en contra de dicha sentencia. El juzgado de Curuguaty rechaza la acción de defensa presentada por el Estado, ante lo cual se lleva el caso a la Cámara de Apelaciones quien decide levantar la inscripción del inmueble a nombre de Riquelme y anularla, con lo cual dicha propiedad vuelve a quedar registrada a nombre de la Industrial Paraguaya, ya que por "alguna razón” nunca se había inscripto a nombre del Estado paraguayo.

${ }^{8}$ En el contexto de la álgida tensión por el tema de la reforma agraria, tanto en 2010 cuanto en 2011 el gobierno de Lugo decretó el Estado de Excepción en la región del Chaco con motivo de la aparición del autodenominado "Ejército del Pueblo Paraguayo" (EPP). Esta decisión se tomó en gran medida como producto de la presión del Congreso, la patronal agraria y algunos medios de comunicación (UHARTE POZAS, 2012).
} 
Lo cierto es que la presión de la patronal agraria y las élites tradicionales representadas en la ANR y el PLRA evitaron cualquier avance en esta materia y se encargaron de iniciar una campaña de desprestigio en contra del jefe del Ejecutivo. En suma, el destino de Lugo estuvo marcado por una serie de factores institucionales y coyunturales que terminaron por activar la figura disuasoria más empleada por la élite parlamentaria paraguaya desde 1992: el juicio político. Como sostiene PérezLiñán (2012), en Paraguay todo parecería indicar que además de un abuso de esta figura, hay un estiramiento más que notorio de la misma, haciéndola parecer más a la moción de censura parlamentaria que a un mecanismo propio y muy específico del presidencialismo.

La interrupción del mandato de Fernando Lugo deja tras de sí varias cuestiones a tomar en cuenta: a) que Lugo era "un intruso en casa ajena" que representaba una amenaza a las élites tradicionales tanto políticas como económicas; b) la APC era una coalición contra natura en la que los que tenían todo que perder eran los partidos más a la izquierda en un contexto marcadamente conservador; c) la experiencia paraguaya deja bajo relieve que los outsiders difícilmente pueden sobrevivir en un entorno en el que sus apoyos son muy frágiles o nulos y en el que las buenas intenciones no bastan para gobernar; y d) es notoria la radicalización de posturas y el reforzamiento en la valoración de instituciones tradicionales y fuertemente conservadoras.

Tras el juicio político, los meses posteriores a éste estuvieron caracterizados por la criminalización de la lucha social, la persecución policial que hizo el gobierno liberal sobre algunos líderes campesinos y la muerte de algunos de ellos en circunstancias no esclarecidas. Asimismo, otras cuestiones que caracterizaron a los meses que mediaron entre la destitución del presidente y el comienzo de las campañas electorales fue el despido masivo de trabajadores de la administración pública que estuvieron acompañados de movilizaciones y huelgas por parte de los sindicatos de las instituciones públicas; y finalmente, los casos de corrupción en que se vieron involucrados varios funcionarios liberales que se sirvieron con la cuchara grande en los últimos meses del mandato constitucional. Al final del camino todo quedó en el opareí, palabra de origen guaraní que su emplea para indicar algo que termina en la nada o algo que pasa en la indiferencia colectiva sin tener alguna consecuencia (STABILI, 2012). 


\section{Las flexibles reglas del juego y el ambiguo carnaval de las ofertas electorales}

En términos formales, la campaña electoral tiene una duración de 60 días. De esta manera, y siempre de acuerdo con el Código Electoral, las actividades proselitistas comprenderían del 18 de febrero al 18 de abril, sin embargo, el inicio de las campañas se adelantó por mucho a la fecha establecida, sin que por ello la autoridad electoral sancionara a los partidos que incurrieron en esta violación. Esto es un buen preámbulo, si se quiere entender que en Paraguay, a pesar de que existen en términos generales reglas claras, los actores políticos se manejan con cierta soltura, a sabiendas de que no habrá sanciones por jugar ciertas cartas fuera de la ley.

Lo anterior es especialmente notorio cuando se observa la composición del Tribunal Superior de Justicia Electoral (TSJE), en el que prevalece la repartición por cuotas de los magistrados que lo conforman entre los principales partidos políticos del país. Esto quiere decir que en la medida en que los propios partidos controlan y se distribuyen los asientos del TSJE saben que las sanciones serán menguadas o improbables, pero por otro lado, y quizás más importante que lo anterior, es que asumen que controlar el mayor número de posiciones es vital para salvaguardar sus intereses o incluso para levantar cortinas de humo o sacar ventaja en los propios procesos electorales. De acuerdo con esto resulta significativo cuando algunos de sus miembros ponen en entredicho, como ocurrió durante la jornada electoral del 21 de abril $^{9}$, la imparcialidad del árbitro electoral, que por otro lado es seriamente cuestionado por las fuerzas políticas cuyo peso electoral es más reducido.

Sobre estas bases, la campaña electoral paraguaya se distinguió por ser muy asimétrica entre los principales partidos (ANR y PLRA) y el resto de competidores, en cuanto los primeros no sólo contaban con más recursos económicos, sino que además tuvieron mayores coberturas por los medios masivos de comunicación. A este respecto, es muy importante destacar que, a pesar del avance en la difusión de las distintas plataformas a través de las redes sociales, en Paraguay sigue predominando un modelo tradicional de hacer campaña basado principalmente en la explotación de la imagen y presencia de los candidatos a través de canales como la televisión, la radio, la prensa escrita y los mítines, en los que los ciudadanos pueden tener contacto físico con los candidatos.

\footnotetext{
${ }^{9}$ El ministro y vicepresidente del TSJE, Juan Manuel Morales, dio declaraciones a la prensa durante la jornada electoral refiriendo que existía una favorable a uno de los candidatos y que ésta sería irreversible. Es conocido que el ministro Morales tiene una vinculación de larga data con la ANR.
} 
Algunos de los aspectos en donde se pueden reflejar esas asimetrías fueron los distintos debates entre presidenciables y la cantidad de minutos que otorgaban las televisoras a Horacio Cartes y Efraín Alegre, así como las páginas de prensa que los principales diarios (ABC Color y Última Hora) dedicaban a ellos. Con relación a los debates, los partidos más pequeños mostraron su inconformidad en la medida en que fueron excluidos de estos ejercicios y no pudieron contrastar con sus adversarios sus programas y propuestas, a pesar de que en ellos fue más claro observar los ofrecimientos de todos los candidatos. Mientras que con respecto a la inequitativa aparición en medios, una buena explicación estriba en las lagunas que existen en la ley electoral en cuanto ésta no fija topes de campaña y no existen mecanismos claros para la fiscalización y procedencia de los recursos que se destinan a las actividades proselitistas, tema del cual se hablará más adelante.

En este proceso electoral se presentaron 11 fórmulas para competir por la presidencia de la república. Al tratarse de elecciones concurrentes con aquellas para diputados y senadores, la atención se concentró en la campaña presidencial, dejando así a los otros comicios a la suerte de lo que pasara en la contienda por el Ejecutivo. De acuerdo con los informes de las misiones electorales, tanto de la Organización de los Estados Americanos (OEA) (MOE-OEA, 2013) cuanto de la Unión Europea (UE) (MOE-UE, 2013), la campaña se desarrolló en un entorno pacífico, no obstante, es importante destacar que el tono empleado por Cartes y Alegre se fue elevando en la medida en que se acercaba el cierre de las campañas, y con ello la polarización se hizo más evidente. En suma, las campañas se distinguieron por los pobres contenidos en programas y propuestas y una explotación de la imagen personal de los candidatos aunados al cruce de acusaciones. A modo de ejemplo, fueron recurrentes los señalamientos que los liberales hicieron sobre el pasado del candidato colorado, sus posibles vínculos con el narcotráfico y el modo cómo amasó su fortuna. Mientras que la ANR explotó las supuestas infidelidades maritales de Efraín Alegre, a raíz de la exposición que éste último y su equipo de campaña hicieron de su familia, misma que era exhibida como modélica, prototípica y tradicional del Paraguay ${ }^{10}$.

Por otro lado, el papel desempeñado por el gobierno en funciones, encabezado por Federico Franco, fue muy cuestionado dada la intervención directa que la administración a su cargo hizo a favor de los candidatos del PLRA. Sobre este punto, fue común la intervención de los candidatos liberales en actos de gobierno como inauguración de obras públicas y también la participación de funcionarios en

${ }^{10}$ Para ahondar sobre estos aspectos, véase Hoy (2013). 
actos proselitistas a favor de este partido (MOE-UE, 2013). Además de esto, la implicación del gobierno liberal en funciones no sólo se constriñó a lo antes mencionado, sino que contribuyó con recursos públicos a financiar las campañas de sus candidatos a los distintos cargos de elección, ello sin dejar de lado los señalamientos de corrupción que saltaron en la prensa, entre los que destacan la compra irregular por parte del Instituto Nacional de Desarrollo Rural y de la Tierra (INDERT) de una estancia al padre del líder oviedista y presidente en ese momento del congreso nacional, Jorge Oviedo Matto, al mismo tiempo que liberales y oviedistas cerraban una alianza para las elecciones del 21 de abril.

La inesperada muerte de Lino Oviedo, líder indiscutible de UNACE y otrora figura central en el golpe de Estado que depuso a Alfredo Stroessner en 1989, así como de los acontecimientos que a la postre fueron conocidos como el "Marzo Paraguayo" en 1999, dio cuenta que su agrupación política giraba en torno a su persona y que sin él, el partido perdería su esencia y su influencia sobre una parte nada despreciable del electorado ${ }^{11}$.

Por su parte, los partidos más a la izquierda del espectro político experimentaron una notoria fragmentación producto del desgaste y de las condiciones de salida del Poder Ejecutivo tras el juicio político expeditivo al que fue sometido Fernando Lugo. Asimismo, y a raíz de esto, estos partidos acrecentaron sus divisiones en la medida en que no lograron consensuar una candidatura común y fragmentaron el voto de sus simpatizantes. En ese sentido, la figura de Fernando Lugo jugó un papel muy importante ya que el ex presidente en un primer momento ofreció la candidatura del Frente Guazú al conductor de televisión Mario Ferreiro y a la postre - una vez desposeído del cargo - se retractó e incluso insinúo que él mismo podría ser el candidato presidencial ya que la constitución no se lo impedía (LA NACIÓN, 2012a).

Por lo que respecta a los programas y propuestas presentados por los distintos partidos y alianzas, cabe destacar que estos se caracterizaron por su pobreza y ambigüedad de contenidos, es decir, que se privilegió la promoción personal de los candidatos y sus "virtudes" como líderes exitosos en los distintos campos en los que se

\footnotetext{
${ }^{11}$ UNACE era hasta antes de la muerte de Lino Oviedo la tercera fuerza política del país y aglutinaba alrededor del 9\% de los votos. Los resultados de la elección de 2013 así confirmaron la debacle del partido en cuanto UNACE apenas alcanzó el 6\% de votos en la elección para Diputados y el 3,7\% para Senadores. El lamentable accidente aéreo de Oviedo, además de dejar en la orfandad a su partido, despertó las sospechas entre sus correligionarios de que éste bien pudo haber sido víctima de un atentado, teoría muy ad hoc a las ideas de conspiración que en todo momento y para todo esgrimía el propio general extinto.
} 
desempeñaban antes de optar por la presidencia, ya sea como empresarios, gestores o conductores de televisión. A pesar de ello, los principales temas que se trataron durante la campaña, siempre tomando en cuenta su ambigüedad, fueron: pobreza, empleo, seguridad, salud, educación y reforma judicial ${ }^{12}$.

Cuadro 1 - Principales temas abordados por los candidatos presidenciales en campaña

\begin{tabular}{|c|c|c|c|c|c|c|}
\hline & $\begin{array}{c}\text { Horacio } \\
\text { Cartes }\end{array}$ & $\begin{array}{l}\text { Efraín } \\
\text { Alegre }\end{array}$ & $\begin{array}{c}\text { Mario } \\
\text { Ferreiro }\end{array}$ & $\begin{array}{c}\text { Aníbal } \\
\text { Carrillo }\end{array}$ & $\begin{array}{c}\text { Miguel } \\
\text { Carrizosa }\end{array}$ & Lilian Soto \\
\hline Pobreza & $\checkmark$ & $\checkmark$ & $\checkmark$ & - & - & $\checkmark$ \\
\hline Empleo & $\checkmark$ & $\checkmark$ & $\checkmark$ & - & $\checkmark$ & $\checkmark$ \\
\hline Seguridad & $\checkmark$ & $\checkmark$ & - & - & $\checkmark$ & $\checkmark$ \\
\hline Salud & $\checkmark$ & $\checkmark$ & $\checkmark$ & $\checkmark$ & $\checkmark$ & $\checkmark$ \\
\hline Educación & $\checkmark$ & $\checkmark$ & $\checkmark$ & $\checkmark$ & $\checkmark$ & $\checkmark$ \\
\hline Juventud & $\checkmark$ & - & - & - & - & $\checkmark$ \\
\hline $\begin{array}{c}\text { Reforma } \\
\text { Agraria }\end{array}$ & - & - & $\checkmark$ & $\checkmark$ & - & $\checkmark$ \\
\hline $\begin{array}{c}\text { Reforma } \\
\text { Tributaria }\end{array}$ & - & - & $\checkmark$ & $\checkmark$ & - & $\checkmark$ \\
\hline Pymes & - & - & - & - & $\checkmark$ & - \\
\hline $\begin{array}{c}\text { Reforma } \\
\text { Judicial }\end{array}$ & - & $\checkmark$ & $\checkmark$ & $\checkmark$ & $\checkmark$ & $\checkmark$ \\
\hline
\end{tabular}

Fuente: Elaboración propia con base en las páginas web de los candidatos y la página web denominada A quiénes elegimos del CIRD (2013).

\section{La procelosa y dilatada senda de la selección de candidatos}

De acuerdo con el artículo 154 del Código Electoral Paraguayo (Ley 834/96), la selección de candidatos para el Periodo Electoral Nacional, que comprende la elección de Presidente, Diputados, Senadores, Gobernadores y Concejales Departamentales, ha de realizarse a través de elecciones primarias al interior de los distintos partidos o alianzas, en cualquier domingo entre los 90 y 135 días previos a la

12 Para ahondar sobre este tema, bien vale la pena hacer una revisión hemerográfica de las campañas, en donde se da cuenta de las declaraciones de los distintos candidatos en sus respectivos mítines, y en las que se reflejan la enorme ambigüedad de las propuestas y los lugares comunes de sus planteamientos. 
cita electoral. Con base en este mandato, las candidaturas que se presentaron para la contienda presidencial tuvieron procesos de selección tan controvertidos como disímiles.

En el caso del candidato colorado Horacio Cartes, éste fue construyendo su candidatura presidencial desde el año 2009, en lo que se podría denominar una estrategia de campaña permanente. Cartes, un auténtico outsider, ofreció como su carta de presentación el éxito que como empresario lo ha colocado en muy poco tiempo como uno de los hombres más ricos del país, y un modelo a seguir. Ante la crisis al interior del coloradismo tras la derrota en las elecciones de 2008 y la ausencia de liderazgos fuertes que garantizaran la unidad del partido, la ANR fichó a Cartes en cuanto éste reunía el carisma, simpatía y popularidad necesarios que no existía entre los barones del partido si querían recuperar la presidencia de la república. Con ese propósito, la ANR modificó incluso sus estatutos, de tal suerte que Horacio Cartes pudiera ser su candidato presidencial a pesar del rechazo e inconformidad de una parte de la militancia del partido que veía en él a un advenedizo que sólo estaba allí para beneficiar a sus empresas ${ }^{13}$. Al final, Cartes fue investido como candidato tras vencer en un proceso interno a Javier Zacarías Irún en diciembre de $2012^{14}$.

Efraín Alegre, a la postre candidato presidencial por el oficialista PLRA, obtuvo la candidatura presidencial tras una procelosa disputa con Blas Llano. Alegre es un político con amplia trayectoria que se ha desempeñado, entre otras cosas, como Ministro de Obras Públicas y Comunicaciones, diputado nacional y senador. La imagen que desde un principio se quiso proyectar de él era la del buen gestor y promotor de la transparencia. Sin embargo, su camino a la candidatura liberal estuvo lleno de polémicas, ya que los resultados de la consulta realizada a los afiliados a través de las llamadas "urnas delivery" fueron controversiales, dado el ajustado resultado (menos del 1\%), a favor de Llano ${ }^{15}$. Esto produjo una crisis al interior del PLRA que duró ocho meses y que estuvo dominada por la intransigencia y la incomprensión entre efrainistas y llanistas, y que sólo fue resuelta tras el anuncio de

\footnotetext{
${ }^{13}$ Las modificaciones realizadas se basaron concretamente en los años de militancia que debería reunir un miembro del partido para optar por la candidatura presidencial o cualquier otro cargo de relevancia por parte de la ANR, al pasar de 10 años a tan solo uno.

14 En esta elección interna, Cartes obtuvo el 59,6\% de los sufragios, mientras que su adversario Zacarías Irún alcanzó el 33,5\% de los votos colorados (LA NACIÓN, 2012b).

${ }^{15}$ Se conoce como "urnas delivery" al mecanismo que permite llevar al domicilio de los afiliados los materiales de votación a fin de que éstos sufraguen sin tener que salir de sus casas. En la consulta celebrada bajo esta modalidad por los liberales el 1 de abril de 2012, los resultados fueron los siguientes: Blas Llano con 18,917 votos y Efraín Alegre con 18,698 votos (PPN, 2012).
} 
Blas Llano de renunciar a su aspiración presidencial en una convención del partido, lo que abrió paso a unas elecciones internas con candidatos de menor envergadura, y con la consigna de sacar adelante una candidatura de consenso, lo que benefició a Efraín Alegre quien finalmente obtuvo la nominación liberal.

Entre las candidaturas de la izquierda paraguaya, la protagonizada por Mario Ferreiro fue la que mayor interés y cobertura recibió por parte de los medios de comunicación. Ferreiro, un conocido conductor de programas de revista matutina con amplia trayectoria en la televisión decidió aceptar la invitación de Fernando Lugo para abanderar al Frente Guazú mientras éste último aún era presidente. Por las razones ya expuestas en el epígrafe anterior, el juicio político a Lugo no sólo produjo una fragmentación en el campo de la izquierda, sino que además trajo consigo la falta de acuerdos necesarios para construir una candidatura única. Al final, Ferreiro fue postulado por la plataforma Avanza País (un conglomerado de partidos como el Partido Movimiento al Socialismo (P-MAS), el Partido Revolucionario Febrerista (PRF), el Partido Demócrata Cristiano (PDC) y otros) tras un proceso interno de candidatura única para la chapa presidencial. El resto de partidos, como Patria Querida (PPQ) KuñáPyrendá, UNACE, el Partido Demócrata Progresista (PDP), entre otros, realizaron procesos internos conforme a lo establecido en el Código Electoral vigente ${ }^{16}$.

\section{El diseño institucional y la caja negra de la financiación}

De acuerdo con la Ley Electoral del país, el sufragio es obligatorio para todos los ciudadanos habilitados. El sistema de elección presidencial en Paraguay es de mayoría simple, es decir, que obtiene el triunfo quien más votos concentre en una sola vuelta electoral. Este sistema, así como aquel de segunda vuelta con umbral reducido, se asocia con la participación de un menor número de candidatos relevantes así como de menos partidos con representación en el Congreso (PAYNE y ALLAMAND, 2006 [2002]). De igual manera, este tipo de sistema tiende a que los candidatos ganadores obtengan porcentajes muy cercanos al 50\% (ver Tabla 3), así se corrobora en las distintas elecciones celebradas en el país desde 1989.

Por otro lado, de acuerdo con la Constitución Nacional la duración del mandato presidencial es de cinco años sin posibilidad de reelección. Esto se debe en buena medida al hiperpresidencialismo experimentado durante los años de la dictadura de Alfredo Stroessner (1954-1989) quien modificó consecutivamente la

\footnotetext{
${ }^{16}$ Con relación a la candidatura de Mario Ferreiro se pueden consultar algunas notas de prensa como las siguientes: ABC Color (2012); Paraguay.com (2012); Última Hora (2012).
} 
Constitución de 1967 para ser reelecto, primero, por otros dos periodos a partir de 1968, y luego en 1977, por tiempo indefinido. En ese sentido también es relevante mencionar que la Asamblea Constituyente de 1992 confeccionó un diseño institucional tal en el que el congreso posee mayores facultades que el presidente con el objetivo de limitar a este último con base en la experiencia previa vivida bajo el stronismo.

Por lo que respecta a la elecciones legislativas (diputados y senadores) éstas se realizan simultáneamente a la presidencial. La cámara de diputados paraguaya está compuesta por 80 bancas, mientras que la de senadores por 45. La forma de elección para estos cargos se realiza a través de listas cerradas y bloqueadas en circunscripciones medianas y la conversión de votos en escaños se realiza aplicando la fórmula de D’Hondt, que es la más utilizada en América Latina. Para tal efecto, en la elección para diputados, el país se divide en 18 circunscripciones, cuya magnitud promedio es de 4.4, que representan a los 17 departamentos y a la capital, mientras que para la cámara alta, el país se constituye en una sola circunscripción nacional (PAYNE, 2006 [2002]).

De acuerdo con la Constitución Nacional los requisitos para postularse a los diferentes cargos de elección popular son los siguientes: para presidente, tener nacionalidad paraguaya natural, haber cumplido 35 años y estar en pleno ejercicio de sus deberes políticos y cívicos; para diputado y senador, tener nacionalidad paraguaya natural y haber cumplido 25 y 35 años, respectivamente.

Siguiendo las disposiciones del Código Electoral (PARAGUAY, 1996) ${ }^{17}$, la duración de las campañas es de 60 días. En este periodo, los partidos, movimientos políticos y alianzas pueden difundir sus mensajes en la vía pública, así como a través de los medios de comunicación. Sin embargo, en Paraguay ni los plazos ni los mecanismos de fiscalización son efectivamente cumplidos, es decir, que existe una disparidad entre la letra de la ley y su cumplimiento.

Con base en esto, se señala que en materia de financiamiento político si bien el sistema ofrece de manera declarativa igualdad entre los competidores, los controles para detectar el origen de los recursos que llegan a las campañas son frágiles y de difícil seguimiento (BAREIRO y ECHAURI, 2011). En otras palabras, es un sistema que no controla el dinero que circula ni en las elecciones internas ni en las elecciones generales. En Paraguay, la financiación de los partidos políticos y de las campañas es mixta, es decir, que hay una mezcla entre recursos públicos y privados, que además no establece topes de campaña lo que termina generando enormes asimetrías entre

${ }^{17}$ Ley 834/96. 
quienes pueden acceder a mayores recursos y aquellos que no pueden hacerlo. Del mismo modo, la fragilidad institucional permite que exista una enorme opacidad en los aportes que reciben las campañas porque si bien en la letra existe un límite a los donativos privados no se prohíben las contribuciones anónimas. En el mismo tenor, no existen mecanismos lo suficientemente fuertes para investigar y sancionar el desvío de recursos públicos que el gobierno nacional o las administraciones locales pueden canalizar a las campañas de los candidatos de sus respectivos partidos. En el contexto del proceso electoral de 2013, las misiones electorales tanto de la Unión Europea como de la OEA hicieron notar que estas situaciones se manifestaron en las campañas del PLRAy de la ANR ${ }^{18}$.

\section{Los resultados electorales en perspectiva sincrónica y diacrónica}

a) A nivel agregado nacional

El proceso electoral de 2013 dejó como claro vencedor de los comicios a la ANR que tras cinco años en la oposición recuperó la Presidencia de la República de la mano del empresario Horacio Cartes, y afirmó su mayoría tanto en diputados cuanto en senadores. En la elección presidencial, la ANR obtuvo el 45,8\% de los votos, mientras su más cercanocompetidor, el PLRA, consiguió el 36,9\% de los sufragios válidos. La participación en este proceso fue de $68,5 \%$ de los ciudadanos inscritos en el padrón electoral ${ }^{19}$.

En cuanto a la elección legislativa, el Partido Colorado alcanzó el triunfo tras haber conseguido el $38,3 \%$ de los votos para diputados y el 35,9\% en senadores. El resto de formaciones políticas tuvieron resultados disímiles que oscilaron entre el $1 \%$ y el $27 \%$ de los votos. A este respecto, cabe destacar el pobre desenvolvimiento de partidos como UNACE y el PPQ, frente al mejor desempeño de agrupaciones como Frente Guazú y Avanza País, a pesar de la fragmentación de la izquierda. Por su parte, el PLRA mantuvo los resultados que en promedio ha obtenido históricamente cuando se presenta en solitario.

\footnotetext{
${ }^{18} \mathrm{Al}$ respecto se puede consultar: Moe-Oea (2013), o bien: ABC Color (2013).

19 Es particularmente llamativo que el candidato colorado Horacio Cartes ejerció en este proceso electoral por primera vez su derecho al voto, según él mismo lo señaló en conferencia de prensa celebrada al día siguiente de la elección (PEREGIL, 2013).
} 
Tabla 1 - Porcentaje de votos obtenido por partido para cada categoria de orden nacional (2013)

\begin{tabular}{c|c|c|c}
\hline Partidos & Presidente & Senadores & Diputados \\
\hline ANR & 45,8 & 35,9 & 38,3 \\
\hline PLRA & 36,9 & 24,0 & 27,3 \\
\hline Avanza País & 5,8 & 4,8 & 3,5 \\
\hline Frente Guazú & 3,3 & 9,9 & 5,1 \\
\hline PPQ & 1,1 & 1,8 & 2,6 \\
\hline UNACE & 0,8 & 3,7 & 6,1 \\
\hline PEN & & 3,2 & 4,5 \\
\hline PDP & & 6,0 & 1,2 \\
\hline APC & 0,7 & & 0,6 \\
\hline Otros partidos & 2,9 & 3,3 & 3,9 \\
\hline Votos blancos & 2,4 & 3,3 & 3,6 \\
\hline Votos nulos & 100 & 3,2 & 2,8 \\
\hline TOTAL & & 100 & 100 \\
\hline
\end{tabular}

Fuente: Elaboración propia con base en los datos del TSJE.

b) Elecciones previas

$\mathrm{Al}$ analizar los procesos electorales presidenciales anteriores en perspectiva comparada desde 1998 se encuentra que la ANR es un partido que con el paso del tiempo fue perdiendo su caudal de votos, a raíz de la escisión que se dio en esa formación política y del surgimiento de un grupo de empresarios católicos que dieron paso a nuevos partidos como UNACE y PPQ. Estos últimos concentraron el voto más conservador, así como las simpatías de los sectores militaristas que conforme avanzó la transición fueron desplazados.

Al observar los procesos de 2003 y 2008 se puede caer en cuenta que ambas formaciones mermaron ostensiblemente el rendimiento de la ANR, por lo que llama mucho la atención el desplome que tuvieron en este último proceso electoral de 2013 al apenas aglutinar al $1,9 \%$ de las preferencias electorales, lo que en buena medida quiere decir que muchos de sus electores volvieron al redil colorado, o bien se desplazaron a otras propuestas políticas de la derecha como el Partido Encuentro Nacional (PEN). Esto a causa de la muerte de referentes como Lino Oviedo, al retiro del escenario político de figuras como Pedro Fadul, o bien por la concertación de alianzas sorprendentes como la que cerraron el PLRA y UNACE ${ }^{20}$.

${ }^{20}$ En un intento desesperado el PLRA pactó una alianza con el partido del extinto general golpista Lino Oviedo (UNACE) pensando, quizás de manera ilusoria, que automáticamente todos los votantes de este partido trasvasarían su confianza a los liberales (SÓLIS DELGADILLO y CERNA VILLAGRA, 2013). 
Por lo que toca al desempeño del PLRA, llama la atención que en tres de las cuatro últimas elecciones ha ido en alianza con partidos tan distintos como disímiles ideológicamente hablando, y que en la única oportunidad en la que se presentó en solitario, sus resultados han sido los más deficientes, lo que en buena medida explica que este partido necesita de socios, aunque estén en las antípodas de su ideología, para ser competitivo. Así lo atestigua el resultado de 2008 cuando triunfó con una alianza contra natura que respaldó la candidatura del ex obispo Fernando Lugo (Ver Tabla 2).

Tabla 2 - Porcentaje de votos de cada partido para la elección de Presidente (1998-2013)

\begin{tabular}{c|c|c|c|c}
\hline Partidos & $\mathbf{1 9 9 8}$ & $\mathbf{2 0 0 3}$ & $\mathbf{2 0 0 8}$ & $\mathbf{2 0 1 3}$ \\
\hline ANR & 53,8 & 37,1 & 30,7 & 45,8 \\
\hline PLRA & 42,6 & 24 & & \\
\hline APC & & & 40,9 & \\
\hline APA & & & & 36,9 \\
\hline UNACE & & 13,5 & 22 & 0,8 \\
\hline PPQ & & 21,3 & 2,4 & 1,1 \\
\hline Avanza País & & & & 5,9 \\
\hline Frente Guazú & & & & 3,3 \\
\hline Participación electoral & 80,5 & 64,3 & 65,6 & 68,6 \\
\hline
\end{tabular}

*Alianza Democrática entre PLRA y Partido Encuentro Nacional.

APC: Alianza Patriótica para el Cambio, alianza entre PLRA y otros partidos.

APA: Alianza Paraguay Alegre entre PLRA y UNACE.

Fuente: Elaboración propia con base en los datos del TSJE. La Alianza Democrática (AD) (1998) estuvo conformada entre el PLRA y el Partido Encuentro Nacional. La Alianza Patriótica para el Cambio (APC) (2008) fue liderada por el PLRA en compañía de otros partidos de izquierda. La Alianza Paraguay Alegre (APA) (2013) fue integrada por liberales y UNACE tras la muerte de Lino Oviedo.

Las sucesivas elecciones para elegir diputados nacionales en Paraguay muestran que conforme han pasado los años son más las formaciones políticas las que se disputan los votos de los ciudadanos. De esta manera, mientras en 1998 eran sólo los partidos tradicionales (ANR y PLRA) quienes se repartían más del 90\% de los sufragios, es a partir de 2003 que el voto se empieza a fragmentar, principalmente a la derecha con el surgimiento de partidos como UNACE y PPQ. Esta tendencia se ratificó en la elección de 2008, en la que si bien la contienda presidencial fue ganada por una alianza que permitió que un puñado de partidos de izquierda accediera al gobierno de la mano de los liberales, el resultado de la elección legislativa dejó de manifiesto que el $25 \%$ del electorado prefería con claridad a estos partidos antes que depositar su confianza en los socios de Lugo que estaban más a la izquierda del espectro político. 
No obstante, el último proceso electoral de 2013 arroja una cuestión por demás interesante, ya que si bien la ANR como el PLRA han mantenido estables sus apoyos electorales en este tipo de elección, es evidente que agrupaciones como Frente Guazú o Avanza País, claramente a la izquierda del espectro político, disputan con UNACE y PPQ el espacio como tercera fuerza en el país, sin dejar de mencionar que todos estos partidos se encuentran muy lejos de competir a los partidos tradicionales ${ }^{21}$. Un claro ejemplo de cómo se ha transformado la competencia electoral en Paraguay lo refleja la evolución del Número Efectivo de Partidos (NEP) que ha pasado de 1,74 en 1993 a 4,32 en 2013 (Ver Tabla 5).

Tabla 3 - Porcentaje de votos de cada partido para la elección de Diputados (1998-2013) (\%)

\begin{tabular}{c|c|c|c|c}
\hline Partidos & $\mathbf{1 9 9 8}$ & $\mathbf{2 0 0 3}$ & $\mathbf{2 0 0 8}$ & $\mathbf{2 0 1 3}$ \\
\hline ANR & 53,8 & 35,3 & 32,9 & 38,3 \\
\hline PLRA & 42,7 & 25,7 & 28,2 & 27,3 \\
\hline UNACE & & 14,7 & 18,7 & 6,1 \\
\hline PPQ & & 15,3 & 5,7 & 2,6 \\
\hline PEN & & 3,1 & & 4,5 \\
\hline PPS & & 3,3 & 1,6 & 1,2 \\
\hline PDP & & & 3,6 & \\
\hline MPT & & & 1,6 & 3,5 \\
\hline PMAS & & & & 5,1 \\
\hline Avanza País & & & & 0,6 \\
\hline Frente Guazú & & & & \\
\hline APC & & & & \\
\hline
\end{tabular}

Fuente: Elaboración propia con base en los datos del TSJE.

Finalmente, por lo que corresponde a la Cámara de Senadores, y al igual de lo que ha ocurrido en diputados, es interesante observar la manera en la que se ha venido fragmentando el voto de los paraguayos a partir de 2003, y cómo esa fragmentación se ha ido dando, primero entre los partidos más a la derecha, y paulatinamente, como si se tratara de un péndulo, entre los partidos más a la izquierda quienes ademáshan ido adquiriendo más fuerza y representación. En ese

\footnotetext{
${ }^{21}$ Sobre este aspecto, es dramática la caída en las preferencias de UNACE y PPQ, si se toma en cuenta que en dos periodos bien pudieron ejercer una capacidad de chantaje importante en función del porcentaje de votos que acapararon.
} 
sentido basta con observar de igual manera la evolución del NEP en este tipo de elección que ha pasado de 2,28 en 1998 a 4,97 en 2013 (Ver Tabla 5).

Tabla 4 - Porcentaje de votos de cada partido para la elección de Senadores (1998-2013) (\%)

\begin{tabular}{c|c|c|c|c}
\hline Partidos & $\mathbf{1 9 9 8}$ & $\mathbf{2 0 0 3}$ & $\mathbf{2 0 0 8}$ & $\mathbf{2 0 1 3}$ \\
\hline ANR & 51,7 & 32,9 & 29 & 35,9 \\
\hline PLRA & 42,1 & 24,3 & 28,9 & 24,4 \\
\hline UNACE & & 13,7 & 19,2 & 3,7 \\
\hline PPQ & & 15,2 & 8,6 & 1,8 \\
\hline Encuentro Nacional & & 2 & 1,1 & 3,2 \\
\hline PPS & & 4,4 & 3,4 & \\
\hline PDP & & & 2,1 & 6 \\
\hline MPT & & & 2,9 & \\
\hline Avanza País & & & & 4,8 \\
\hline Frente Guazú & & & & 9,9 \\
\hline
\end{tabular}

Fuente: Elaboración propia con base en los datos de Elecciones Paraguay Global y TSJE.

c) Composición del Poder Legislativo por partidos o grupos parlamentarios

Al traducir los votos en escaños se encuentra que el Partido Colorado ha recuperado la mayoría absoluta (55\%) en la Cámara de Diputados después de 15 años, mientras que en el Senado también ha ganado terreno al ocupar 20 de las 45 bancas de la cámara (44\%). Estos resultados vienen a confirmar la doble victoria que en el proceso electoral 2013 alcanzó la ANR, pues no sólo logró retornar a la Presidencia de la República, sino que también obtuvo sus mejores resultados en la elección legislativa desde 1998. De acuerdo con el Gráfico 2, se puede apreciar que tras la ANR, en la Cámara de Diputados el PLRA ha mantenido su peso en el arco parlamentario al colocar 27 legisladores (33\%), mientras que el resto de escańos se reparten casi equitativamente entre los partidos más conservadores (UNACE, PEN y PPQ) que acaparan el seis por ciento de las bancas y aquellos más a la izquierda (Avanza País, Frente Guazú y Alianza Pasión Chaqueña) que ocupan el cinco por ciento de las mismas.

Por su parte, en la Cámara de Senadores, el Gráfico 3 permite observar una cuestión que no está por demás mencionar, y que gira en torno al claro desplazamiento de los partidos más conservadores por parte de aquellos más a la izquierda que en estas últimas elecciones han logrado introducir en esta cámara el mayor número de legisladores de esta orientación ideológica (nueve) desde que 
retornó la democracia en 1989. Esto es llamativo porque a pesar de las fricciones entre partidos de izquierda parece ser que los ciudadanos cuando son representados en un gran distrito nacional prefieren plataformas más centristas frente a la retórica radical de aquellos partidos que se ubican más a la derecha del espectro ideológico.

Gráfico 2 - Composición de la Cámara de Diputados 2013-2018

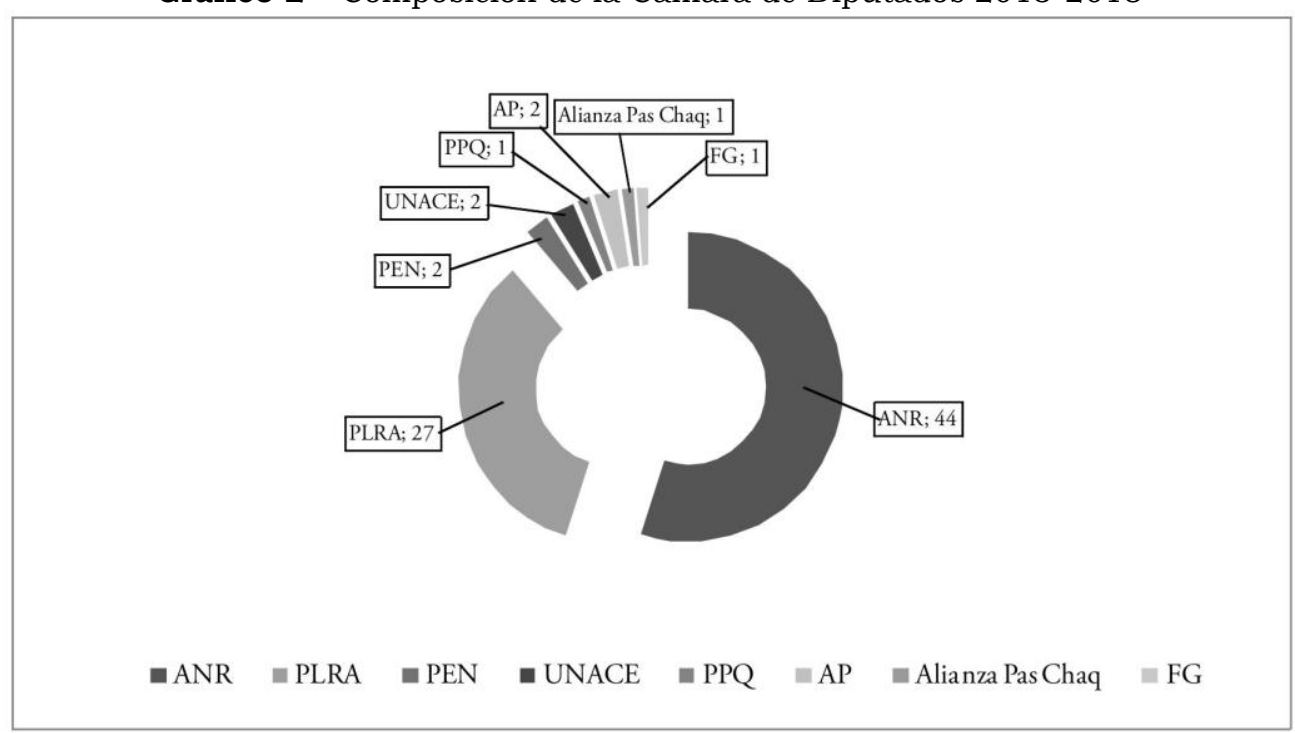

Fuente: Elaboración propia con base en los datos del TSJE.

Gráfico 3 - Composición de la Cámara de Senadores 2013-2018

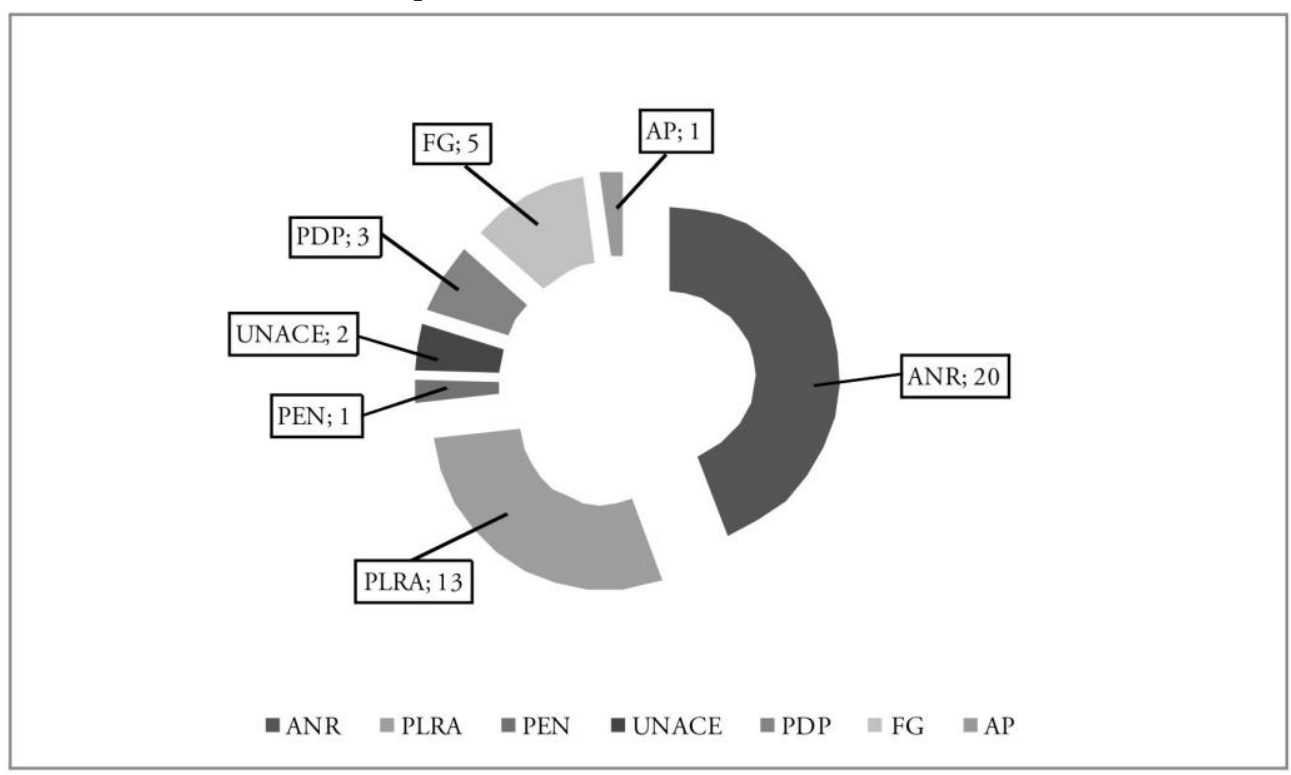

Fuente: Elaboración propia con base en los datos del TSJE. 
Al calcular el Número Efectivo de Partidos (NEP) en los distintos tipos de elecciones desde el año de 1993 se puede apreciar que el Paraguay ha experimentado desde entonces una paulatina evolución de un sistema de partido hegemónico hacia uno de pluralismo limitado (SARTORI, 2009 [1976]). Con base en esto, es importante destacar que desde la elección de 2003, el sistema de partidos dio un salto significativo en cuanto un mayor número de partidos se tornaron relevantes, principalmente en las cámaras legislativas. La Tabla 5 da cuenta de la evolución del NEP electoral para los distintos cargos de elección de 1993 a 2013.

Tabla 5 - Evolución del NEP paraguayos 1993-2013

\begin{tabular}{l|c|c|c|c|c}
\hline & $\mathbf{1 9 9 3}$ & $\mathbf{1 9 9 8}$ & $\mathbf{2 0 0 3}$ & $\mathbf{2 0 0 8}$ & $\mathbf{2 0 1 3}$ \\
\hline Presidente & 1,68 & 2,18 & 3,91 & 3,34 & 2,91 \\
\hline Diputados & 1,74 & 2,19 & 4,21 & 4,39 & 4,32 \\
\hline Senadores & & 2,25 & 4,75 & 4,66 & 4,97 \\
\hline
\end{tabular}

Fuente: Elaboración propia con base en los datos del Elecciones Paraguay Global.

Por lo que respecta a la volatilidad, el análisis comparado de los datos desde 1993 permite mostrar que en los distintos tipos de elección ésta ha oscilado entre 20 y 30\%, por lo que la volatilidad (PEDERSEN, 1979) experimentada en este país es moderada en cuanto la media en la variación de los resultados de votación obtenidos para presidente, diputados y senadores en los últimos cinco procesos electorales es de 25,69 .

Tabla 6 - Volatilidad agregada en Paraguay 1993-2013

\begin{tabular}{l|c|c|c|c|c}
\hline & $\mathbf{1 9 9 3}$ & $\mathbf{1 9 9 8}$ & $\mathbf{2 0 0 3}$ & $\mathbf{2 0 0 8}$ & $\mathbf{2 0 1 3}$ \\
\hline Presidente & 32,95 & 23,75 & 35,05 & 25,35 & 25,4 \\
\hline Diputados & 33,3 & 17,75 & 35,95 & 15,85 & 19,45 \\
\hline Senadores & & 17,1 & 35,95 & 13,85 & 29,65 \\
\hline
\end{tabular}

Fuente: Elaboración propia con base en los datos del Elecciones Paraguay Global.

En perspectiva comparada, al analizar la evolución de la composición de ambas cámaras en Paraguay se extraen tres lecturas: la primera de ellas corrobora el repunte que el proceso electoral de 2013 ha traído para la ANR al recuperar la mayoría absoluta en diputados y al incrementar notablemente su mayoría en senadores. Este reposicionamiento del coloradismo es muy llamativo ya que tras cinco años en la oposición, una buena cantidad de paraguayos volvieron a depositar la confianza en el viejo partido hegemónico, quizás debido al desencanto con la gestión de la frágil APC, la destitución del presidente Lugo y la polémica administración de 
unos cuantos meses de los liberales. Estas circunstancias probablemente incidieron en el ánimo de los ciudadanos quienes añorando la "pax colorada" depositaron nuevamente su confianza en la ANR, aun y cuando el partido se encontraba en la crisis de liderazgo más grande de su historia y se tuvo que valer de una figura externa y advenediza para erigir una plataforma atractiva. En pocas palabras, la suma de los errores de sus adversarios y los aciertos de los colorados al ser pragmáticos dieron pie a la reconfiguración de la fuerza de la ANR en ambas cámaras.

La segunda lectura que se extrae tras analizar los datos históricos de composición de las últimas tres legislaturas tanto en diputados cuanto en senadores es que el PLRA es un partido que pase lo que pase ha mantenido firmes y estables sus apoyos, lo que se traduce en su inalterado porcentaje de escaños en las dos cámaras. Esto llama mucho la atención, sobre todo porque tras el último año y después de la ruptura de la alianza con Fernando Lugo, su destitución y la polémica gestión del gobierno que hicieron desde entonces y hasta agosto de 2013, daría la impresión que los ciudadanos ni castigaron ni premiaron al partido por sus actuaciones en esos distintos momentos decisivos en los últimos cinco años.

Finalmente, la tercera lectura que se obtiene de analizar la evolución de las cámaras es que ha habido un notorio repliegue de los partidos más conservadores en contraposición de la cada vez mayor presencia de los partidos más a la izquierda del espectro ideológico. La mayor presencia de éstos últimos no se puede despreciar porque su auge en las cámaras ha permitido que el Poder Legislativo adquiera una composición más plural. Por otro lado, el vaciamiento de partidos como UNACE, y en especial de PPQ dan cuenta de la caducidad de sus discursos en la medida en que sus máximos referentes ya no están en la arena política con lo que sus electores al quedar en la orfandad han emigrado para refugiarse en otras formaciones políticas ${ }^{22}$.

\footnotetext{
${ }^{22}$ Una buena muestra de ello es que los dos hijos del fallecido líder de la UNACE, Ariel y Fabiola Oviedo han renunciado a tomar el testigo del liderazgo de su padre en aquella formación política y han vuelto al redil del Partido Colorado (LA NACIÓN, 2013).
} 
212 | Sarah Patricia Cerna Villagra e Juan Mario Solís Delgadillo

Tabla 7 - Composición de la Cámara de Diputados 1998-2013

\begin{tabular}{|c|c|c|c|c|}
\hline & 1998 & 2003 & 2008 & 2013 \\
\hline ANR & 45 & 37 & 30 & 44 \\
\hline PLRA & 26 & 21 & 27 & 27 \\
\hline PEN & 7 & & & 2 \\
\hline \multicolumn{5}{|l|}{ PB } \\
\hline UNACE & & 10 & 15 & 2 \\
\hline PPQ & & 10 & 3 & 1 \\
\hline PPS & 2 & 2 & & \\
\hline MPT & & & 1 & \\
\hline PDP & & & 1 & \\
\hline APC & & & 2 & \\
\hline $\mathrm{ADB}$ & & & 1 & \\
\hline $\mathrm{AP}$ & & & & 2 \\
\hline Alianza Pas Chaq & & & & 1 \\
\hline FG & & & & 1 \\
\hline TOTAL & 80 & 80 & 80 & 80 \\
\hline
\end{tabular}

Fuente: Elaboración propia con base en los datos del TSJE, OIR (2013) y Paraguay Global. 
Tabla 8 - Composición de la Cámara de Senadores 1998-2013

\begin{tabular}{c|c|c|c|c}
\hline & 1998 & 2003 & 2008 & 2013 \\
\hline ANR & 24 & 16 & 15 & 20 \\
\hline PLRA & 13 & 12 & 14 & 13 \\
\hline PEN & 7 & 1 & & 1 \\
\hline PB & 1 & & 9 & 2 \\
\hline UNACE & & 7 & 4 & \\
\hline PPQ & & 7 & 1 & 3 \\
\hline PPS & & 2 & 1 & 5 \\
\hline MPT & & & & 1 \\
\hline PDP & & & 45 & 45 \\
\hline FG & & 45 & & \\
\hline AP & & & & \\
\hline TOTAL & 45 & & & \\
\hline
\end{tabular}

Fuente: Elaboración propia con base en los datos del Elecciones Paraguay Global.

\section{Escenarios que se abren de cara al futuro}

Mirando hacia adelante, y sin afán de hacer predicciones sobre lo que ocurrirá en los próximos años en Paraguay políticamente hablando, hay una serie de escenarios que se pueden abrir, y ante los cuales los politólogos han de estar atentos a dar seguimiento, según se vaya dando el curso de las cosas. En primer lugar, los primeros meses de gobierno han dado cuenta de que los colorados no le han dado demasiada autonomía al presidente Horacio Cartes; esto era previsible ya que a final de cuentas Cartes es un actor político exógeno al sistema de partidos, sin experiencia en el juego de cintura que se ha de tener para negociar en política con otros actores e intereses. Un vistazo al gabinete presidencial confirma que los propios colorados han flanqueado al presidente con experimentadas figuras del partido en los puestos clave del gobierno con el fin de mantener el control del mismo.

En el plano legislativo será importante dar seguimiento a la agenda, no sólo del presidente Cartes, sino también de aquella que vaya surgiendo de los arreglos que desde ya se están presentando entre colorados y liberales y que se ha dado por llamar como el Pacto Azulgrana, a través del cual ambos partidos han trazado una hoja de ruta común y para promover un gran pacto de gobernabilidad. Para ello, los colorados han cedido la presidencia de la Cámara de Diputados a los liberales, y se especula que estos últimos aceptarían el trueque a cambio de un acuerdo de impunidad que dejaría sin efecto las posibles denuncias por corrupción durante el breve gobierno de Federico Franco (ÚLTIMA HORA, 2013). 
No obstante, y dada la experiencia que ha acompañado a cada uno de los gobiernos democráticos paraguayos tras la promulgación de la Constitución de 1992, no resultaría extraño que las coaliciones que se firmen hoy se rompan en cualquier momento y con ello se interpongan sucesivas y hasta inverosímiles solicitudes de juicio político al presidente (CERNA VILLAGRA y SÓLIS DELGADILLO, 2012; PÉREZ-LIÑÁN, 2009). Con esto se quiere decir que en Paraguay las alianzas han sido históricamente frágiles y en ocasiones se parecen mucho a lo que en el argot de la lucha libre mexicana se conocería como relevos increíbles ${ }^{23}$. Sin embargo, y con las reservas necesarias, el pacto entre colorados y liberales, por más improbable que pareciera hace algunos años, hoy no resulta descabellado, sobre todo en la medida en que ambos partidos se han aproximado mucho en términos ideológicos (PELA, 2008).

En cuanto a lo que se espera del resto de partidos/actores del sistema político paraguayo, cabe la posibilidad de que partidos como UNACE y PPQ se enfilen al colapso si no son capaces de reprogramar sus propuestas políticas, y si al mismo tiempo no encuentran reemplazo a las figuras históricas que les dieron razón de ser. Por su parte, el futuro de la izquierda puede depender mucho de su desempeño en las cámaras legislativas y en la capacidad que desde las bancas que dominan tengan para hacer contrapeso, por mínimo que sea, a la maquinaria del Pacto Azulgrana.

De particular interés será la postura que adopten todos los partidos de cara a una posible reforma del sistema de justicia que casi todas las plataformas, excepto la ANR, prometieron promover durante la campaña. Esto en sí es muy importante, ya que el Poder Judicial, al igual que en toda la región, ha sido el que más ha demorado en democratizarse, sobre todo porque más que un tercer poder ha sido visto tradicionalmente como un poder de tercera (FIERRO, 2003). De la mano de esto, habrá que esperar el derrotero que tomen las políticas públicas, especialmente aquellas de corte social teniendo en cuenta que este tema ha sido el caballo de batalla de Horacio Cartes durante la campaña electoral.

Finalmente, será interesante observar y dar seguimiento a las condiciones y desempeño que juegue el Paraguay en el Mercosur, sobre todo tras la incorporación de Venezuela que fue aceptada durante la suspensión del país guaraní después de la crisis institucional de 2012. En ese sentido, la performance del nuevo presidente será de vital importancia dada su proclividad a emitir comentarios no sólo políticamente incorrectos sino a todas luces desatinados.

\footnotetext{
${ }^{23}$ Se llaman relevos increibles a las contiendas en las que luchadores de bandos totalmente opuestos (rudos y técnicos) luchan juntos por motivos meramente de conveniencia.
} 


\section{A manera de conclusión}

Al momento de explicar el voto, es decir, la voluntad de los ciudadanos expresada en las urnas se puede realizar una lectura desde tres dimensiones: los ganadores; los perdedores; y las implicaciones que tienen esos resultados.

Por lo que respecta a los primeros, no cabe la menor duda que el gran triunfador del proceso electoral de 2013 en Paraguay ha sido el Partido Colorado, no sólo por su pronto regreso a la Presidencia de la República, tan solo un periodo después de haberla perdido, sino porque ha obtenido sus mejores resultados electorales de los últimos 20 años, y ello le ha servido para robustecer su fuerza legislativa en las cámaras. Lo anterior demuestra una cosa e invita a la reflexión sobre otra cuestión: que la ANR es el partido más nacionalizado en el Paraguay, y que a pesar de su salida del poder en 2008 jamás perdió su poder territorial; en segundo término, que en medio de la crisis de liderazgos visibles y aglutinadores, el partido optó por ser pragmático y alinearse tras la atractiva figura de un outsider que se presentaba como la realización de un paraguayo exitoso. La cuestión aquí sería preguntarse qué tan dispuesto está el partido de seguir alineado a Cartes, o qué tan posible será que el partido lo fagocite a él.

Los grandes perdedores de la contienda electoral de 2013 han sido las formaciones más conservadoras del sistema de partidos paraguayo: UNACE y PPQ. Esto es así no sólo por el exiguo caudal de votos que obtuvieron en esta elección, sino por la estrepitosa caída en el número de escaños que ocupan en la actual legislatura en comparación con los que llegaron a dominar en 2003 y 2008. Sobre esta debacle, cabe apuntar, en primer término, que la ausencia de sus máximos líderes demostró que sin ellos estos partidos carecían de contenido (porque eran vehículos electorales hechos a la medida de sus dirigentes); y, en segundo lugar, que el perfil del votante de estos partidos (clases medias y altas, urbanas y religiosas) votaron por Horacio Cartes o por el viejo PEN.

Por otro lado, y por sorprendente que sea, el PLRA mantuvo el caudal electoral que le reporta su electorado fiel, aun y cuando tuvo una participación proactiva en la promoción del juicio político de su otrora socio Fernando Lugo, y a pesar de los desatinos como presidente interino de Federico Franco y los escándalos de corrupción y desvío de recursos públicos de la administración nacional a favor de los candidatos liberales que bien le pudieron haber pasado un castigo más alto por parte de los electores. Esto en sí llama la atención pero corrobora una cuestión: que en Paraguay no se pena tan severamente la felonía y la corrupción como sí se premia a la opacidad y la superficialidad. 
En cuanto a los partidos de la izquierda está claro que han tenido un mejor desempeño electoral que el mostrado en 2008, sin embargo las disputas y la fragmentación de este campo no garantiza que puedan crear una agenda común para hacer un contrapeso mínimamente significativo a la que presentarán tanto la ANR cuanto el PLRA. A pesar de ello, no se puede menospreciar su crecimiento si se toma como referencia el nuevo periodo democrático inaugurado desde 1989 en el que han pasado de la participación simbólica a la competencia y conquista de escaños.

En suma, cuando se trata de analizar las implicaciones que arrojan los resultados de este último proceso electoral en Paraguay se pueden hacer cuatro consideraciones: que el único partido con una estructura y efectiva presencia nacional es la ANR; en segundo lugar, que el PLRA es un partido incapaz de crecer, que mantiene su voto cautivo y que éste se nuclea en los Departamentos de Central, Cordillera, Neembucú y Amambay; seguidamente, que UNACE y PPQ son partidos en vías de extinción en cuanto se han vaciado de contenido a raíz de la ausencia de sus líderes históricos, y porque buena parte de su electorado concentrado en las principales ciudades del país no tienen mayor problema en encontrar cobijo en otras opciones políticas de la derecha como lo puede ser la ANR o el PEN; y, por último, que la izquierda paraguaya, a pesar de sus diferencias, ha tenido un crecimiento interesante en las zonas rurales, pero también entre grupos de las clases medias urbanas menos conservadoras y religiosas. Con todo, Paraguay se ha ido transformando de manera gradual pero consistente, en una democracia pluralista y relativamente estable a pesar de las crisis institucionales que ha protagonizado, en buena medida por el diseño institucional adoptado desde 1992.

- Sarah Patricia Cerna Villagra é Doutoranda em Ciências Políticas e Sociais da Universidade Nacional Autônoma do México e em Doutorado em Estado de Direito e Governança Global pela Universidade de Salamanca, e é bolsista do CONACYT, no México. E-mail: sacervi@hotmail.com.

- Juan Mario Solís Delgadillo é Professor Investigador da Faculdade de Direito da Universidade Autônoma de São Luís Potosí no México. E-mail: juanmariosolis@gmail.com. 


\section{Referências}

ABC COLOR. Entrega de dinero es poco clara, dice UE. 10 jun. 2013. Disponible en: $<$ http://www.abc.com.py/edicion-impresa/politica/entrega-de-dinero-es-poco-clara-dice-ue582621.html>. Aceso en: 15 jun. 2013.

. Mario se rebela y hoy dejaría el Frente Guasu. 8 out. 2012. Disponible en: <http://www.abc.com.py/edicion-impresa/politica/mario-se-rebela-y-hoy-dejaria-el-frente-guasu460650.html>. Aceso en: 17 jun. 2013.

ABENTE BRUN, Diego A. Estatalidad y calidad de la democracia en Paraguay. América Latina Hoy, n. 60, p. 43-66, 2012.

ALCÁNTARA SÁEZ, Manuel. La crisis paraguaya desde la perspectiva de sus legisladores. Infolatam, 8 jul. 2012. Disponible en: <http://www.infolatam.com/2012/07/09/la-crisis-paraguaya-desde-laperspectiva-de-sus-legisladores>. Aceso en: 10 set. 2012.

BAREIRO, Line; ECHAURI, Carmen. Financiamiento de la política en Paraguay. In: GUTIÉRREZ, Pablo; ZOVATTO, Daniel (Coords.). Financiamiento de los partidos politicos en América Latina. Ciudad del México: UNAM, IIJ, IDEA, OEA, 2011. p. 417-443.

BARREDA, Mikel; BOU, Marc. La calidad de la democracia paraguaya: un avance sobre caminos tortuosos. América Latina Hoy, Salamanca, n. 56, p. 133-161, dez. 2010.

CERNA VILLAGRA, Sarah P.; DELGADILLO, Juan M. S. La crisis institucional de 2012 a la luz de las élites parlamentarias. Boletín Élites Parlamentarias Latinoamericanas, Salamanca, n. 42, out. 2012.

CIRD. Centro de Información y Recursos para el Desarrollo. A quienes elegimos. Asunción: CIRD, 2013. Disponible en: <http://elecciones.aquieneselegimos.org.py/>. Aceso en: 17 jun. 2013.

ELECCIONES PARAGUAY GLOBAL. Elecciones Generales 1993-1998. Disponible en: $<$ http://elecciones.pyglobal.com/>. Aceso en: 18 jun. 2013.

FIERRO, Héctor F. La reforma judicial en México: ¿de dónde viene? ¿hacia dónde va? In: JENSEN, Eric; HELLER, Thomas (Eds.). Beyond common knowledge: Empirical approaches to the rule of law. Palo Alto: Standford University Press, 2003.

HOY. Campaña sucia: Atacan a Cartes y ahora salta "amante" de Efraín. 28 feb. 2013. Disponible en: $<$ http://www.hoy.com.py/politica/campaa-sucia-atacan-a-cartes-y-ahora-salta-amante-de-efran>. Aceso en: 15 jun. 2013.

LA NACIÓN. Lugo da la espalda a Mario Ferreiro y a Sixto y piensa en su candidatura. 10 out. 2012a. Disponible en: <http://www.lanacion.com.py/articulo/94123-lugo-da-la-espalda-a-marioferreiro-y-a-sixto-y-piensa-en-su-candidatura-.html>. Aceso en: 16 jun. 2013.

LA NACIÓN: TREP de ANR certifica triunfo de Cartes. 9 de diciembre de 2012b. Disponible en: http://www.lanacion.com.py/articulo/103815-trep-de-anr-certifica-triunfo-de-cartes.html. Aceso en: 20 de jun. 2013.

LA NACIÓN. Dos hijos de Lino Oviedo hoy vuelven al Partido Colorado. 16 nov. 2013. Disponible en: <http://www.lanacion.com.py/articulo/147281--dos-hijos-de-lino-oviedo-hoy-vuelven-al-partidocolorado.html>. Aceso en: 23 mar. 2014.

MAG. Ministerio de Agricultura y Ganadería. Resultados preliminares del Censo Agropecuario Nacional 2008. 2009. Disponible en: <http://www.mag.gov.py/presentacioncan2008.pdf>. Aceso en: 25 mar. 2014.

MOE-OEA. Misión de Observación Electoral en Paraguay de la Organización de Estados Americanos. Informe verbal. Asunción, 2013. 
MOE-UE. Misión de Observación Electoral en Paraguay de la Unión Europea. Informe final: Elecciones generales 21 de abril de 2013. Asunción, 2013.

OIR. Observatorio de Instituciones Representativas. Legislatina. Universidad de Salamanca, 20082013. 2013. Disponible en: <http://americo.usal.es/oir/legislatina/paraguay.htm>. Aceso en: 16 jun. 2013.

PALAU, Tomás. La política y su trasfondo: El poder real en Paraguay. Revista Nueva Sociedad, Buenos Aires, n. 229, p. 134-150, set-out. 2010.

PARAGUAY. Ley n ${ }^{\circ}$ 834, de 17 de abril de 1996. Código Electoral Paraguayo. Disponible en: <http://tsje.gov.py/legislacion/leyes/1996/5_834.pdf>. Aceso en: 12 jun. 2013.

PARAGUAY.COM. Mario Ferreiro confirma su candidatura presidencial. 9 abr. 2012. Disponible en: $<$ http:/www.paraguay.com/nacionales/mario-ferreiro-confirma-su-candidatura-presidencial81619>. Aceso en: 17 jun. 2013.

PAYNE, Mark. Sistemas de elección legislativa y gobernabilidad democrática. In: PAYNE, Mark; ZOVATTO, Daniel; DÍAZ, Mercedes M. La política importa: Democracia y desarrollo en América Latina. Washington, D.C.: Planeta, 2006 [2002]. p. 41-89.

PAYNE, Mark; ALLAMAND, Andrés. Sistemas de elección presidencial y gobernabilidad democrática. In: PAYNE, Mark; ZOVATTO, Daniel; DÍAZ, Mercedes M. La política importa: Democracia y desarrollo en América Latina. Washington, D.C.: Planeta, 2006 [2002]. p. 19-39.

PEDERSEN, Mogens. Electoral Volatility in Western Europe, 1848-1977. European Journal of Political Research, v. 7, n. 1, p. 1-26, 1979.

PELA. Elites Parlamentarias Latinoamericanas. Estudio 69: Paraguay. Encuesta a Diputados Paraguayos 2008-2013. Universidad de Salamanca, 2008. Disponible en: $<$ http://americo.usal.es/oir/elites/Eliteca/datosagregados/Paraguay/Marginales_Paraguay_69[1].pdf >. Aceso en: 13 set. 2013.

PEREGIL, Francisco. El nuevo presidente de Paraguay admite que nunca en su vida había votado. El País, 23 abr. 2013. Disponible en: http://internacional.elpais.com/internacional/2013/04/23/actualidad/1366676793_086760.html Aceso en: 10 jun. 2013.

PÉREZ-LIÑÁN, Aníbal. Juicio Politico al presidente y nueva inestabilidad política en América Latina. Ciudad del México: Fondo de Cultura Económica, 2009.

PÉREZ-LIÑÁN, Aníbal P. Paraguay: futuro incierto, con rebote regional. Clarín, 27 jun. 2012. Disponible en: <http://www.clarin.com/opinion/Paraguay-futuro-incierto-reboteregional_0_726527445.html>. Aceso en: 13 sept. 2012.

PPN. Llano fue proclamado como ganador de las urnas delivery. 7 de abril de 2012. Disponible en: <http://www.ppn.com.py/html/noticias/noticia-ver.asp?id=82182\&rss=go >. Aceso en: 16 jun. 2013.

SANDOVAL, Luis O. Causas y efectos de un golpe institucional. Revista Acción, Asunción, n. 326, p. 7-12, jul. 2012.

SARTORI, Giovanni. Partidos y sistemas de partidos. Madrid: Alianza Editorial, 2009 [1976].

SÓlIS DELGADILlO, Juan M. S.; CERNA VILLAGRA, Sarah P. C. Costumbres guaraníes: elecciones y retos, ¿fin del culebrón? Condistintos acentos, 19 abr. 2013. Disponible en: $<$ http://www.condistintosacentos.com/costumbres-guaranies-elecciones-y-retos-fin-del-culebron>. Aceso en: 18 jun. 2013. 
STABILI, María R. Opareí: La justicia de transición en Paraguay. América Latina Hoy, Salamanca, n. 61, p. 137-162, abr. 2012.

TRANSPARENCIA INTERNACIONAL. Corruption Perceptions Index 2013. Berlín, 2013. Disponible en: <http://cpi.transparency.org/cpi2013/results>. Aceso en: 28 mar. 2014.

TSJE. Tribunal Superior de Justicia Electoral de Paraguay. Disponible en: <http://tsje.gov.py>

UHARTE POZAS, Luis Miguel. El proceso de democratización paraguayo: avances y resistencias. América Latina Hoy, Salamanca, n. 60, p. 17-42, abr. 2012.

ÚLTIMA HORA. Frente Guasu y Avanza País desnudan sus conflictos en las redes sociales. 25 dez. 2012. Disponible en: <http://www.ultimahora.com/notas/587723-Frente-Guasu-y-Avanza-Paisdesnudan-sus-conflictos-en-las-redes-sociales>. Aceso en: 19 jun. 2013.

. Se confirma pacto azulgrana a base de cargos y se oficializará el viernes. 19 jun. 2013. Disponible en: <http:/www.ultimahora.com/notas/627381-Se-confirma-pacto--azulgrana-a-basede-cargos-y-se-oficializara-el-viernes>. Aceso en: 26 jun. 2013.

Texto recebido em 10 de setembro 2013. Aprovado em 25 de março de 2014. 
